\title{
Leite cru refrigerado: qualidade microbiológica, físico-química e detecção de
}

\section{resíduos de antibióticos}

\author{
Refrigerated raw milk: microbiological, physical-chemical quality and detection of antibiotic \\ residues
}

Leche cruda refrigerada: calidad microbiológica, físico-química y detección de residuos antibióticos

Recebido: 22/11/2021 | Revisado: 28/11/2021 | Aceito: 10/01/2022| Publicado: 12/01/2022

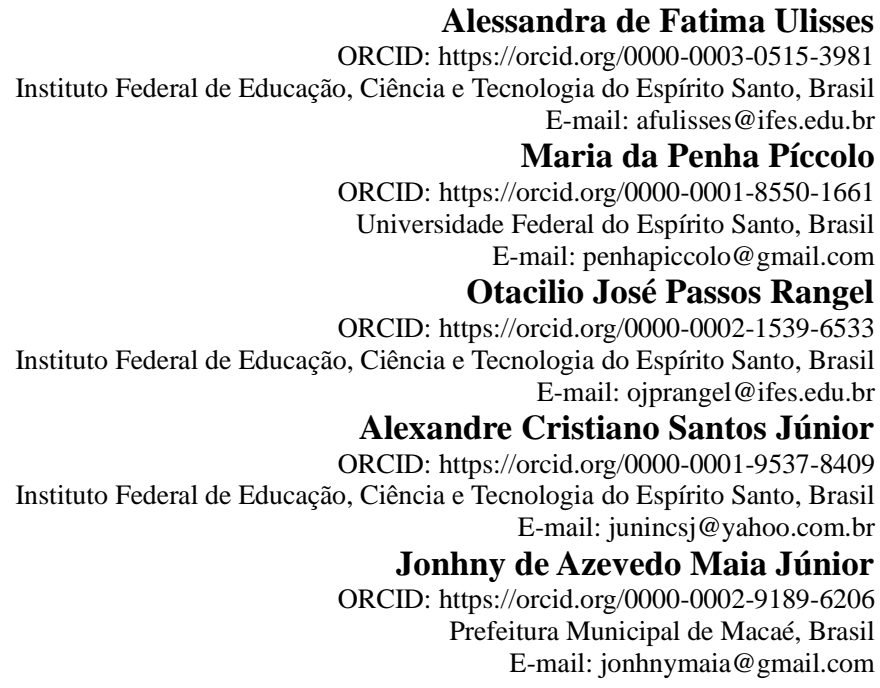

\section{Resumo}

Objetivou-se avaliar a qualidade microbiológica, físico-química além da verificação da presença de resíduos de antibióticos em amostras de leite cru refrigerado coletadas em quatro tanques individuais e cinco coletivos localizados em propriedades rurais pertencentes ao município de Alegre/ES. As amostras foram codificadas, acondicionadas em frascos esterilizados e transportadas ao Laboratório de Microbiologia e Biotecnologia do Instituto Federal do Espírito Santo Ifes, Campus de Alegre/ES. Realizou-se análises microbiológicas para contagem bacteriana total e Staphylococcus aureus; físico-químicas; além da detecção de resíduos de antibióticos dos grupos $\beta$-lactâmicos e tetraciclinas. Os valores médios para CBT ficaram entre 2,0 x $10^{4} \mathrm{UFC} \mathrm{mL}^{-1}$ e $3,0 \times 10^{7} \mathrm{UFC} \mathrm{mL}^{-1}$ e constatou-se que $44,44 \%$ das amostras encontravam-se em conformidade com a legislação. Os valores de $S$. aureus ficaram entre $<10^{2}$ e $3,6 \times 10^{6}$ UFC $\mathrm{mL}^{-1}$ e estes resultados são preocupantes devido à possibilidade de formação de toxinas termorresistentes, além de ser um microrganismo causador de mastite. Em relação às análises físico-químicas, 33,33\% encontraram-se em conformidade com a legislação e em todas as amostras não foram constatados resíduos de antibióticos. Concluiu-se que apenas as amostras coletadas nos tanques de refrigeração individuais $A_{6} \mathrm{e}_{7}$, se encontraram de acordo com a legislação vigente. São necessárias mudanças nas práticas de manejo adotadas para obtenção de leite com qualidade e inocuidade. A adoção dessas medidas permitiria a obtenção de leite com qualidade e inocuidade além de contribuir para a saúde dos consumidores e para a sustentabilidade do setor na região e no estado do Espírito Santo.

Palavras-chave: Agricultura familiar; Leite cru refrigerado; Qualidade microbiológica; Staphylococcus aureus; Tanque de refrigeração.

\footnotetext{
Abstract

The objective was to evaluate the microbiological and physical-chemical quality, in addition to verifying the presence of antibiotic residues in refrigerated raw milk samples collected in four individual and five collective tanks located in rural properties belonging to the municipality of Alegre/ES. The samples were coded, placed in sterilized vials and transported to the Laboratory of Microbiology and Biotechnology of the Federal Institute of Espírito Santo Ifes, Campus de Alegre/ES. Microbiological analyzes were performed for total bacterial count and Staphylococcus aureus; physicochemical; in addition to the detection of residues of antibiotics from the $\beta$-lactam and tetracycline groups. The mean values for TBC were between $2.0 \times 10^{4} \mathrm{CFU} \mathrm{mL}^{-1}$ and $3.0 \times 10^{7} \mathrm{CFU} \mathrm{mL}^{-1}$ and it was found that $44.44 \%$ of the
} 
samples were in compliance with the legislation. The values of $\mathrm{S}$. aureus were between $<10^{2}$ and $3.6 \times 10^{6} \mathrm{CFU} \mathrm{mL}^{-1}$ and these results are worrying due to the possibility of the formation of heat-resistant toxins, in addition to being a microorganism that causes mastitis. Regarding the physicochemical analyses, $33.33 \%$ were in compliance with the legislation and in all samples there were no antibiotic residues. It was concluded that only the samples collected in individual refrigeration tanks $A_{6}$ and $A_{7}$ were in accordance with current legislation. Changes are needed in the management practices adopted to obtain milk with quality and safety. The adoption of these measures would allow obtaining milk with quality and safety, in addition to contributing to the health of consumers and to the sustainability of the sector in the region and in the state of Espírito Santo.

Keywords: Family farming; Good agricultural practices; Refrigerated raw milk; Staphylococcus aureus; Refrigeration tank.

\section{Resumen}

El objetivo fue evaluar la calidad microbiológica y físico-química, además de verificar la presencia de residuos de antibióticos en muestras de leche cruda refrigerada recolectadas en cuatro tanques individuales y cinco colectivos ubicados en predios rurales pertenecientes al municipio de Alegre / ES. Las muestras fueron codificadas, colocadas en viales esterilizados y transportadas al Laboratorio de Microbiología y Biotecnología del Instituto Federal de Espírito Santo Ifes, Campus de Alegre / ES. Se realizaron análisis microbiológicos para el recuento bacteriano total y Staphylococcus aureus; fisicoquímico; además de la detección de residuos de antibióticos de los grupos $\beta$-lactámicos y tetraciclina. Los valores medios de CBT estuvieron entre $2.0 \times 10^{4} \mathrm{UFC} \mathrm{mL}^{-1}$ y $3.0 \times 10^{7} \mathrm{UFC} \mathrm{mL}^{-1}$ y se encontró que $44.44 \%$ de las muestras cumplían con la legislación. Los valores de S. aureus estuvieron entre $<10^{2}$ y $3.6 \times 10^{6}$ UFC $\mathrm{mL}^{-1}$ y estos resultados son preocupantes por la posibilidad de formación de toxinas resistentes al calor, además de ser un microorganismo causante de mastitis. En cuanto a los análisis físicoquímicos, el 33,33\% cumplió con la legislación y en todas las muestras no se encontraron residuos de antibióticos. Se concluyó que solo las muestras recolectadas en los tanques de refrigeración individuales $\mathrm{A}_{6}$ y $\mathrm{A}_{7}$ cumplían con la legislación vigente. Se necesitan cambios en las prácticas de manejo adoptadas para obtener leche con calidad y seguridad. La adopción de estas medidas permitiría obtener leche con calidad y seguridad, además de contribuir a la salud de los consumidores y la sostenibilidad del sector en la región y en el estado de Espírito Santo.

Palabras clave: Agricultura familiar; Leche cruda refrigerada; Calidad microbiológica; Staphylococcus aureus; Tanque de enfriamiento.

\section{Introdução}

No Brasil, o leite é essencial na suplementação alimentar, na geração de emprego e renda de agricultores familiares, estando entre os principais produtos da agricultura. Tudo isso contribui para a diminuição do êxodo rural, por meio de uma nova dinâmica no setor, motivado pelo crescimento da produção nos últimos anos, decorrentes do aumento do rebanho e, principalmente, pelo aumento na produtividade, que nos próximos 10 anos crescerá a uma taxa anual entre 2,1 e 2,9\%. O setor de leite e derivados em 2019 teve um aumento de 2,3\% em relação a 2018, com o consumo formal de 124 litros/hab/ano, porém com a soma do leite não-inspecionado, aproximou-se dos 170 1/hab/ano (Embrapa, 2020).

Vários são os fatores que podem conferir qualidade ao leite cru, desde o estado sanitário do rebanho e manejo; local de ordenha que proporcione conforto e proteção de forma a permitir fácil limpeza do ambiente e dos equipamentos, higienização adequada dos tetos da vaca e eliminação dos primeiros três jatos; armazenamento logo após a ordenha na temperatura adequada no tempo máximo de três horas; transporte até a chegada na indústria e seu beneficiamento (Bozo, et al., 2013; Ramos, et al., 2014; Menezes, et al., 2015; Almeida, et al., 2016; Neta et al., 2016; Neta, et al., 2018; Piccolo, et al., 2018; Teixeira, et al., 2018; Ulisses, et al., 2019).

Apesar da importância da atividade leiteira, trabalhos relatam que em algumas regiões do país o leite cru refrigerado apresenta problemas em relação aos parâmetros de qualidade, mesmo com adoção de várias medidas, podendo tornar-se veículo carreador de microrganismos deterioradores e patogênicos, adquiridos em todas as etapas da cadeia de produção (Neta, et al., 2015; Neta, et al., 2016; Piccolo, et al., 2018; Lampugnani, et al., 2018; Oliveira, et al., 2020; Espíndola, et al., 2020; Carvalho, et al.; 2020). 
O estado do Espirito Santo registra uma média de produção diária de leite de 55 litros por propriedade, totalizando em todo os Estado um rebanho de 213 mil cabeças de animais ordenhados, o que representa 330 milhões de litros de leite produzidos. Os municípios capixabas de Ecoporanga, Presidente Kennedy e Alegre, representam 22\% da produção leiteira no Estado, de acordo com o Sistema de Informações Gerenciais do Serviço de Inspeção Federal (SIGSIF) e vigilância epidemiológica em saúde animal. O município de Alegre se destaca na bovinocultura de leite, como principal atividade de produção animal, de importante relevância socioeconômica, gerando trabalho e renda a vários produtores rurais (Incaper, 2019; Incaper, 2020).

Por meio de trabalhos e visitas técnicas realizadas anteriormente em algumas propriedades rurais do município de Alegre, localizado na região sul do estado do ES, constatou-se algumas características e manejos empregados irregularmente na produção e armazenamento do leite cru refrigerado. Essas inadequações foram em relação à higiene e sanitização, em relação aos utensílios e equipamentos utilizados na ordenha e nos locais dos tanques de refrigeração. Além disso, ficou caracterizada a falta de realização de exames de saúde com o pessoal envolvido no processo, a não realização dos procedimentos de pré-dipping e pós-dipping, bem como a falta de controle da mastite com a realização de testes específicos. A qualidade e inocuidade do leite são prejudicadas pelas condições descritas, associado ao crescimento de microrganismos (Neta, et al., 2015; Neta, et al., 2016; Neta, et al., 2018; Piccolo et al., 2018; Ulisses, et al. 2019).

Mediante o exposto e considerando a importância socioeconômica da pecuária leiteira para o desenvolvimento rural sustentável da agricultura de base familiar objetivou-se avaliar, amostras de leite cru coletadas em nove tanques de refrigeração, a qualidade microbiológica, físico-química e a presença de resíduos de antibióticos, em propriedades rurais pertencentes ao município de Alegre/ES.

\section{Metodologia}

\subsection{Coleta das amostras de leite cru refrigerado}

As amostras de leite cru foram coletadas em nove tanques de refrigeração, sendo quatro individuais e cinco coletivos, com um total de 16 produtores rurais pertencentes a pequenas propriedades rurais do município de Alegre/ES. Coletou-se $500 \mathrm{~mL}$ de leite cru em cada tanque de refrigeração após aferição da temperatura por meio de termômetro com escala de $-10^{\circ} \mathrm{C} \mathrm{a}+110^{\circ} \mathrm{C}$. As amostras foram codificadas como $\mathrm{A}_{1}, \mathrm{~A}_{2}, \mathrm{~A}_{3}, \mathrm{~A}_{4}, \mathrm{~A}_{5}, \mathrm{~A}_{6}, \mathrm{~A}_{7}, \mathrm{~A}_{8}$ e $\mathrm{A}_{9}$, acondicionadas em frascos esterilizados e transportadas em caixas isotérmicas de poliestireno expandido com gelo. Os tanques foram identificados e informações sobre o manejo empregado foram obtidas in loco, de forma que esses dados pudessem contribuir para subsidiar a discussão dos resultados. Todas as análises foram realizadas no Laboratório de Biotecnologia e Microbiologia do Instituto Federal do Espírito Santo (IFES) - Campus de Alegre.

\subsection{Análises microbiológicas}

\subsubsection{Preparo das amostras e diluições seriadas}

As amostras foram previamente homogeneizadas e realizadas diluições seriadas retirando-se $1 \mathrm{~mL}$ de cada amostra e adicionada em frasco contendo $9 \mathrm{~mL}$ de água peptonada a $0,1 \%$, obtendo-se a diluição $10^{-1}$. Deste frasco, foi retirado $1 \mathrm{~mL}$ para outro com $9 \mathrm{~mL}$ de água peptonada, obtendo a diluição $10^{-2}$, e assim, sucessivamente, para os demais tubos, até a diluição $10^{-6}$ para realização das análises microbiológicas.

\subsubsection{Contagem bacteriana total - CBT}

Foram realizadas as análises de CBT por meio de diluições sucessivas em placas de Petri utilizando-se o meio Plate 
Count Agar (PCA) e plaqueamento pour-plate. Seguiu-se a incubação a $35^{\circ} \mathrm{C}$ por 24 a 48 h, realizando-se a seguir a contagem das colônias, cujos resultados foram expressos em UFC mL $\mathrm{mL}^{-1}$, de acordo com metodologia descrita pela American Public Health Association (APHA, 2001).

\subsubsection{Contagem de Staphylococcus aureus}

Foram realizadas as análises por meio da utilização de kit rápido Rida ${ }^{\circledR}$ Count Staph, sendo estas lâminas de cultivo prontas, adicionado de $1 \mathrm{~mL}$ das diluições seriadas selecionadas para cada placa contendo o meio de cultura e incubadas em estufa bacteriológica a $35^{\circ} \mathrm{C}$ por 24 a 48 horas. Após incubação, realizou-se a contagem das colônias, cujos resultados foram expressos em UFC mL $\mathrm{mL}^{-1}$, de acordo com metodologia descrita pelo fabricante.

\subsection{Determinação de resíduos de antibióticos}

Utilizou-se o teste TwinSensor ${ }^{\mathbf{B T}}$ em todas as amostras. É um teste imunoenzimático, com detecção rápida e simultânea de antibióticos dos grupos $\beta$-lactâmicos e tetraciclinas em amostras de leite. As amostras com concentração de antibiótico superior ao limite de detecção do teste foram computadas como positivo. Adicionou-se $200 \mu 1$ de leite no microtubo e misturou-se até obter uma amostra homogênea, seguido de incubação por 3 minutos a $40^{\circ} \mathrm{C}$, sendo em seguida submergida a tira reativa por 3 minutos a $40^{\circ} \mathrm{C}$ para visualização e comparação com as referenciais do manual, de acordo com metodologia descrita pelo fabricante Unisensor, Bélgica.

\subsection{Análises físico-químicas}

As análises físico-químicas foram realizadas em triplicatas de acordo com os procedimentos descritos pela Instrução Normativa $\mathrm{n}^{\circ} 30$ de 26 de junho de 2018 (Brasil, 2018c).

\subsubsection{Determinação do teste de alizarol $72^{\circ} \mathrm{GL}$}

Adicionou-se em um tubo de ensaio $2 \mathrm{~mL}$ da solução de alizarol 72 ${ }^{\circ} \mathrm{GL}$ e $2 \mathrm{~mL}$ de leite cru refrigerado. Após a agitação dos tubos, observou-se a coloração e o aspecto final como a formação de grumos, flocos ou coágulos grandes e coloração, anotando-se posteriormente o resultado. A elevada acidez e desequilíbrio salino leva a coagulação do leite, devido o álcool desestabilizar as micelas. O alizarol é um álcool que possui a alizarina, que é um indicador de pH, que ajuda diferenciando o desequilíbrio salino e a acidez excessiva. Considerando acidez normal e estabilidade ao álcool 72\% v/v as amostras com coloração tijolo sem grumos ou com poucos grumos finos; acidez elevada e não estável ao álcool 72\% v/v as amostras com coloração amarela ou marrom claro, com grumos e presença de mastite ou de neutralizantes amostras com coloração lilás a violeta.

\subsubsection{Determinação da acidez titulável (Método Dornic)}

Transferiu-se $10 \mathrm{~mL}$ da amostra de leite para um béquer de $50 \mathrm{~mL}$. Em seguida, adicionou-se 4 gotas da solução de fenolftaleína a $1 \% \mathrm{~m} / \mathrm{v}$. A acidez titulável foi determinada utilizando a seguinte fórmula: Acidez $\left({ }^{\circ}\right.$ Dornic $)=\mathrm{V} \times \mathrm{f} \times 10$, sabendo-se que cada $1 \mathrm{~mL}$ de $\mathrm{NaOH} 0,1 \mathrm{~N}=0,0090 \mathrm{~g}$ de ácido lático, onde: $\mathrm{V}=$ volume da solução de hidróxido de sódio 0,1 $\mathrm{N}$ gasto na titulação, em mL; $\mathrm{f}=$ fator de correção da solução de hidróxido de sódio N/9; 10 = fator de conversão de ácido lático para graus Dornic. 


\subsubsection{Determinação da densidade a $15^{\circ} \mathrm{C}$}

Adicionou-se $250 \mathrm{~mL}$ de leite para uma proveta lentamente, e logo após, introduziu-se o, Termolactodensímetro Gerber $15^{\circ} \mathrm{C}$, limpo e seco e deixou-se flutuar evitando que o mesmo encostasse na parede da proveta. Foi realizada a leitura da densidade aproximada, após repouso de 1 a 2 minutos na cúspide do menisco e da temperatura no termômetro. O instrumento é provido de termômetro, permitindo a leitura simultânea da densidade e da temperatura, quando o instrumento for utilizado em temperatura diferente de $15^{\circ} \mathrm{C}$ utilizar-se a tabela de conversão que acompanha o instrumento.

\subsubsection{Determinação do teor de gordura (Método de Gerber)}

Transferiu-se para um butirômetro de Gerber, $10 \mathrm{~mL}$ da solução de ácido sulfúrico e logo após $11 \mathrm{~mL}$ de amostra de leite homogeneizada e $1 \mathrm{~mL}$ de álcool isoamílico. Limpou-se os resíduos de reagentes nas bordas com papel toalha e adicionou-se a rolha cônica de borracha, vedando corretamente o butirômetro. $\mathrm{O}$ butirômetro foi envolvido em luva térmica, onde o bulbo maior se localizava na palma da mão e a tampa sendo pressionada pelo dedo polegar para evitar sua projeção. Sendo agitado no interior do aparelho, com precaução de evitar acidente, para uma mistura completa do líquido. Procedeu-se à centrifugação por 5 minutos com rotação de $1200 \mathrm{rpm}$, deixando, logo após, em banho-maria a $65^{\circ} \mathrm{C}$ por 5 minutos. A leitura foi realizada em \% na escala do butirômetro.

\subsubsection{Determinação do extrato seco total (EST) e extrato seco desengordurado (ESD)}

Essas análises foram efetuadas utilizou-se o Disco de Ackermann, que é formado por dois discos sobrepostos. O disco menor, que está por cima, tem graduações correspondentes à densidade $\left(1,020\right.$ a $\left.1,037 \mathrm{~g} \mathrm{~mL}^{-1}\right)$. No disco inferior, que é o maior, há duas ordens de graduações: a primeira, interna, marca a percentagem de gordura (com graduação variando de 0,7 a $6,05 \%$ ) e a segunda marca o extrato seco (com graduação variando de 0,22 a 15,5\%). Para determinar EST, foi coincidindo os valores previamente encontrados de densidade e gordura, fazendo a leitura da matéria seca na escala correspondente onde fica apontada a seta indicadora do valor. Para a obtenção dos valores de ESD foi subtraído o teor de gordura do EST.

\subsection{Análise dos dados}

Os resultados das análises microbiológicas, obtidas em triplicatas, foram apresentados em tabelas com as respectivas médias e desvios padrões de cada variável estudada. As análises físico-químicas foram obtidas por meio de médias das triplicatas realizadas no momento da análise. Para os resíduos de antibióticos verificou-se ausência e presença e os resultados foram comparados aos valores limites estabelecidos pela Instrução Normativa nº 76/2018 (Brasil, 2018a).

\section{Resultados e Discussão}

\subsection{Contagem bacteriana total (CBT), Staphylococcus aureus e detecção de resíduos de antibióticos}

Os resultados da CBT, Staphylococcus aureus e detecção de resíduos de antibióticos em leite cru refrigerado estão apresentados na Tabela 1. 
Tabela 1 - Valores médios e desvio padrão da contagem bacteriana total (CBT), Staphylococcus aureus e detecção de resíduo de antibiótico em amostras de leite cru coletadas em nove tanques de refrigeração pertencentes ao município de Alegre/ES.

\begin{tabular}{|c|c|c|c|c|c|}
\hline $\begin{array}{l}\text { Amostras } \\
\text { de leite }\end{array}$ & Características dos tanques & Tipo de ordenha & 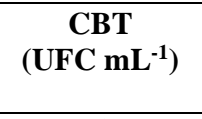 & $\begin{array}{c}\text { Staphylococcus } \\
\text { aureus } \\
\left(\mathrm{UFC} \mathrm{mL}^{-1}\right) \\
\end{array}$ & $\begin{array}{l}\text { Resíduos de } \\
\text { antibióticos }\end{array}$ \\
\hline $\mathbf{A}_{1}$ & Coletivo (03 produtores) & Ordenha Manual & $3,9 \times 10^{5} \pm 2,83$ & $6,0 \times 10^{3} \pm 0,00$ & Ausente \\
\hline $\mathbf{A}_{2}$ & Individual & Ordenha Mecânica & $5,2 \times 10^{6} \pm 7,07$ & $1,2 \times 10^{6} \pm 0,00$ & Ausente \\
\hline $\mathbf{A}_{3}$ & Individual & Ordenha Mecânica & $1,1 \times 10^{6} \pm 7,07$ & $6,0 \times 10^{4} \pm 0,00$ & Ausente \\
\hline A4 & Coletivo (02 produtores) & Ordenha Manual & $3,0 \times 10^{7} \pm 0,00$ & $3,6 \times 10^{6} \pm 0,00$ & Ausente \\
\hline A5 & Coletivo (02 produtores) & Ordenha Mecânica & $1,3 \times 10^{7} \pm 2,83$ & $1,0 \times 10^{5} \pm 0,00$ & Ausente \\
\hline $\mathbf{A}_{6}$ & Individual & Ordenha Mecânica & $2,0 \times 10^{4} \pm 1,41$ & $<10^{2} \pm 0,00$ & Ausente \\
\hline $\mathbf{A}_{7}$ & Individual & Ordenha Mecânica & $6,6 \times 10^{4} \pm 2,83$ & $1,2 \times 10^{3} \pm 0,00$ & Ausente \\
\hline A8 & Coletivo (03 produtores) & Ordenha Manual & $3,0 \times 10^{5} \pm 1,41$ & $6,3 \times 10^{3} \pm 0,00$ & Ausente \\
\hline A9 & Coletivo (02 produtores) & Ordenha Manual & $7,0 \times 10^{4} \pm 1,41$ & $7,3 \times 10^{3} \pm 0,00$ & Ausente \\
\hline $\begin{array}{c}\text { Padrão IN } \\
76 / 2018\end{array}$ & - & - & $3,0 \times 10^{5}$ & $5,0 \times 10^{5}$ & Ausente \\
\hline
\end{tabular}

Fonte: Autores.

De acordo com a Tabela 1, pode-se observar que as amostras codificadas como $A_{1}, A_{2}, A_{3}, A_{4}$ e $A_{5}$ ficaram acima do padrão permitido para CBT, ou seja, $55,55 \%$ não atenderam a legislação vigente com valores acima de $300.000 \mathrm{UFC}^{\mathrm{mL}}{ }^{-1}$. Neste trabalho, verificou-se que o número elevado de microrganismos encontrados foram devidos possivelmente por inadequações em relação às práticas de higiene no momento da ordenha, local de armazenamento, refrigeração por temperaturas inadequadas e acondicionamento nos latões, contribuindo para a qualidade microbiológica inadequada do leite.

$\mathrm{Na}$ amostra $\mathrm{A}_{1}$ constatou-se valores de CBT de 390.000 UFC mL $\mathrm{mL}^{-1}$, acima do limite estabelecido na IN 76/2018 (Brasil, 2018a). As amostras de leite armazenadas nos tanques de refrigeração que apresentaram CBT inferior a 300.000 UFC $\mathrm{mL}^{-1}$ foram as amostras $\mathrm{A}_{6}$ e $\mathrm{A}_{7}$, de tanques individuais, e a $\mathrm{A}_{8}$ e $\mathrm{A}_{9}$ de tanques coletivos. Assim, constatando que $44 \%$ das amostras coletadas e analisadas estavam em conformidade com a IN 76/2018 (Brasil, 2018a), estando as mesmas relacionadas a aplicação de boas práticas de manejo na produção e no local de armazenamento do leite cru.

Quando avaliado as práticas de manejo, que são alternativas para minimizar os riscos de contaminação nas diferentes etapas no processo de produção, observou-se neste trabalho que 44\% (A1, A4, A8 e A9) das propriedades utilizavam ordenha manual e 55\% (A2, A3, A5, A6 e A7) ordenha mecânica, essas informações permitem avaliar que o tipo de ordenha não contribuiu para obtenção de leite com qualidade, caso não estiver associado às boas práticas, como já descrito Ramos, et al. (2014), Neta, et al. (2018), Piccolo, et al. (2018), Teixeira, et al. (2018) e Ulisses, et al. (2019). Ou seja, as amostras coletadas tanto por meio da ordenha manual quanto mecânica apresentaram valores de CBT acima do permitido.

Oliveira et al. (2020), ao avaliarem o leite cru em uma propriedade no município de Mossoró-RN, que realiza ordenha mecânica com balde ao pé, duas vezes ao dia, sendo um total de 84 animais em lactação, verificaram que 50\% das amostras apresentaram contaminação elevada para bactérias mesófilas. Peixoto et al. (2016) relataram em sua pesquisa uma variação nas quantidades de CBT, em função da ordenha, de $1505 \times 10^{3} \mathrm{UFC} \mathrm{mL}^{-1}$ e $979 \times 10^{3} \mathrm{UFC} \mathrm{mL}^{-1}$ para ordenha mecânica e manual, respectivamente, ressaltando que a forma em que o leite é ordenhado não interferiu na qualidade sanitária.

No decorrer de alguns anos no Brasil, o Ministério da Agricultura, Pecuária e Abastecimento (MAPA), vem estabelecendo critérios de padronização e qualidade do leite bovino produzido e oferecido para consumo no país, sendo um deles a identificação e quantificação de alguns grupos específicos de microrganismos que são frequentemente pesquisados, 
como as bactérias aeróbias mesófilas/bactérias totais e Staphylococcus ssp., entre outras. A quantificação das bactérias aeróbias mesófilas é de extrema importância, devido a sua grande predominância em determinados ambientes, e indicativa de qualidade higiênico-sanitária e manejo (Brasil, 2002; Brasil, 2011; Brasil, 2018a; Brasil, 2018b). A ocorrência de resultados elevados fornece indicativo da existência de falhas generalizadas nos procedimentos de ordenha, refrigeração e ambientes nas propriedades leiteiras (Bozo, et al., 2013; Neta, et al., 2015; Neta, et al., 2016; Ramos, et al., 2018; Lampugnani, et al., 2018; Oliveira, et al., 2020; Espíndola, et al., 2020; Carvalho, et al., 2020).

Neta et al. (2016), avaliaram amostras de leite cru refrigerado coletadas em tanques de refrigeração no município de Alegre, ES em trabalho anterior e constataram contagens superiores ao estabelecido na legislação vigente. Segundo os autores altos valores de CBT nas amostras de leite estariam relacionados aos processos de higienização, das condições inapropriadas de produção e nos locais dos tanques de armazenamento, além disso, todos os tanques de refrigeração (100\%) eram coletivos e, neste caso, verificou-se maior risco de contaminação, considerando a mistura de leite proveniente de diversas propriedades rurais.

No âmbito internacional e nacional, a CBT no leite bovino é um critério também utilizado pelas indústrias, produtores e entidades governamentais como indicador da qualidade e da produção higiênica do leite (Rangel, et al., 2013). Bozo et al. (2013), verificaram que após a implantação de boas práticas de ordenha e adoção de recomendações quanto ao tratamento de mastite e a manutenção e higienização dos equipamentos de ordenha houve uma redução média de 93,4\% na CBT, com consequente aumento da renda mensal. Espíndola et al. (2020), constataram que no leite produzido em 86 propriedades na microrregião de Pires do Rio - Goiás, onde 26 possuem ordenha manual e 60 ordenha mecanizada, os parâmetros encontraram-se dentro dos limites mínimos e máximos definidos pela IN 76/2018, sendo o valor médio de CBT de 60,047 x $10^{3} \mathrm{UFC} / \mathrm{mL}^{-1}$.

$\mathrm{Na}$ presente pesquisa, verificou-se que em apenas duas amostras, $\mathrm{A}_{2}$ as quais foram coletadas por meio de ordenha mecânica e tanque individual e $\mathrm{A}_{4}$ por meio de ordenha manual e tanque coletivo respectivamente, o que corresponde a $22,22 \%$ das amostras totais, aos valores de S. aureus (Tabela 1) e se encontravam fora dos padrões preconizados pela legislação vigente acima de $10^{5}$ UFC g- Santana et al. (2006) relatam que casos de intoxicação alimentar podem ser confirmados quando a contagem de $S$. aureus é superiores a $10^{5} \mathrm{UFC} \mathrm{g}^{-1}$, em alimentos contaminados com as bactérias ou com suas enterotoxinas. Valores elevados de Staphylococcus spp. em leite cru coletado de tanques de refrigeração podem ser uma das causas que explica a frequência de surtos de intoxicação estafilocócica na população, sugerindo uma ineficiência nas boas práticas de obtenção do leite e um elevado número de animais com mastite (Lamaita et al., 2005; Assis et al., 2017). Staphylococcus aureus causa toxinfecção por produzir enterotoxina com elevada resistência térmica e pode sobreviver aos tratamentos térmicos comumente aplicados ao leite, como a pasteurização, destacando-se também como a espécie mais frequentemente encontrada nas infecções intramamárias e está envolvida numa grande variedade de doenças em humanos e animais em todos os continentes. A resistência deste microrganismo a antibióticos é preocupante, determinando as maiores perdas na pecuária leiteira (Vasudevan, et al., 2003; Oliveira, et al., 2020).

Estudos realizados por Assis et al., (2017) confirmaram que o principal agente etiológico da mastite bovina em municípios na microregião do Caparaó, que contempla o município de Alegre/ES, é do gênero Staphylococcus spp. (85,91\%), além de ressaltar que o município de Alegre/ES concentrou 47,05\% dos casos de mastite na região.

Neta et al. (2016), ao avaliarem amostras de leite cru refrigerado no município de Alegre/ES, encontraram valores de

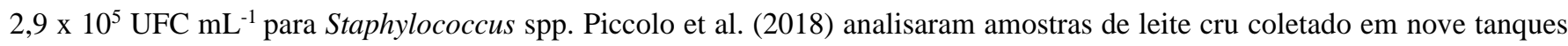
de refrigeração também no município de Alegre/ES e constataram contagens médias de 4,83x $10^{4} \mathrm{UFC} \mathrm{mL}^{-1}$ para $S$. aureus, além de outros grupos microbianos. E afirmam que apesar de não haver padrão estabelecido para $S$. aureus em leite cru 
refrigerado, a presença está relacionada a procedimentos de higienização inadequadas e que os altos valores destas bactérias comprometem a qualidade do leite, podendo acarretar em uma doença transmitidas por alimentos (DTA) e/ou produzir substâncias deletérias, como as toxinas resistentes a pasteurização. Constata-se a necessidade de esforços por parte de todos os envolvidos na cadeia produtiva para que possam se adequar às condições de produção de forma a garantir a inocuidade e qualidade do leite e derivados.

No presente estudo não foram relatados resíduos de antibióticos $\beta$-lactâmicos e tetraciclinas, corroborando com os resultados obtidos por Neta et al. (2016), que também não relataram presença de antibióticos nas amostras analisadas no mesmo município. Porém, Aguiar et al. (2016) relataram, no mesmo município, que 26,70\% de amostras de leite cru refrigerado continham resíduos de antibióticos, ar da utilização de outro teste de detecção, diferente do usado neste trabalho.

Carvalho et al. (2020) avaliaram a ocorrência de resíduos de antibióticos pelo emprego do teste TwinSensor BT® em amostras do leite "in natura" coletadas em seis propriedades localizadas no município de Aquidabã-SE. Os autores verificaram que todas as amostras foram negativas para tetraciclina, porém as amostras de uma propriedade foram positivas para $\beta$ lactâmicos. Além disso, foi observado que os proprietários não conheciam os antibióticos pelo nome do princípio ativo e sim pelo nome comercial e que a prescrição ainda era feita, na grande maioria dos casos, por vendedores de lojas agropecuárias, e que durante a utilização destes medicamentos o destino do leite é sempre a comercialização. Sabe-se que os resíduos apresentam riscos à saúde humana, interferem nas análises diárias realizadas nos laticínios além de promover a resistência bacteriana.

Leite sem resíduos antimicrobianos indica uma boa sanidade animal, controle na hora da ordenha e o cuidado no descarte de leite contaminado (Dürr, 2012). Os antibióticos causam problemas graves quando detectados no leite, atuando como possível causador de problemas de saúde pública, além de causar problemas tecnológicos na indústria em produtos fermentados, inclusive com perda total de alguns processos (Castanheira, 2010; Medeiros, et al., 2017). A utilização de antibióticos, principalmente na pecuária leiteira, é essencial para manutenção da saúde animal, sendo usados para tratar uma variedade de doenças no gado leiteiro, incluindo mastite. No entanto, há uma preocupação global com a resistência a antimicrobianos que causam severos danos à saúde (FAO, 2016).

Após o uso, é preciso esperar o período de carência adequado e exigido para a ordenha, caso contrário pode ser detectado resíduos de antimicrobianos no leite (Toaldo, et al., 2012). Isso pode apresentar sérias consequências toxicológicas e técnicas, pela possibilidade de ocorrer reações alérgicas aos consumidores e provocarem o surgimento de resistência bacteriana (Ávila, et al., 2011), além de ser também um problema econômico e interferir na atuação das culturas láticas utilizadas nos processos tecnológicos de fabricação dos produtos lácteos como queijos, iogurtes e outros produtos (Brito \& Large, 2005; Nunes \& D’Angelino, 2007).

\subsection{Análises físico-químicas do leite cru refrigerado}

Os resultados das análises físico-químicas do leite cru refrigerado, apresentados na Tabela 2, foram comparados com os padrões estabelecidos pela IN 76/2018 (Brasil, 2018a). Essas análises permitem a detecção de fraudes e não conformidades no leite. 
Tabela 2 - Valores médios das análises físico-químicas de amostras de leite cru coletadas em nove tanques de refrigeração localizados no município de Alegre/ES.

\begin{tabular}{|c|c|c|c|c|c|c|c|}
\hline $\begin{array}{l}\text { Amostras } \\
\text { de leite }\end{array}$ & Alizarol & Acidez $^{\circ} \mathbf{D}$ & $\underset{(\mathrm{g} / \mathrm{mL})}{\text { Densidade a } 15^{\circ} \mathrm{C}}$ & $\begin{array}{c}\text { Gordura } \\
(\%)\end{array}$ & $\begin{array}{l}\text { EST } \\
(\%)\end{array}$ & $\begin{array}{c}\text { ESD } \\
(\%)\end{array}$ & $\begin{array}{c}\mathbf{T}^{\circ} \mathrm{C} \\
\text { Tanque de } \\
\text { refrigeração }\end{array}$ \\
\hline $\mathbf{A}_{1}$ & Estável & 15 & $1,029.0$ & 3,7 & 11,93 & 8,23 & 9,3 \\
\hline $\mathbf{A}_{2}$ & Estável & 17 & $1,030.2$ & 4,2 & 12,83 & 8,63 & 4,6 \\
\hline $\mathbf{A}_{3}$ & Estável & 17 & $1,029.4$ & 4,1 & 12,51 & 8,41 & 2,0 \\
\hline $\mathbf{A}_{4}$ & Instável & 20 & $1,030.4$ & 3,2 & 11,68 & 8,48 & 8,3 \\
\hline$A_{5}$ & Instável & 13 & $1,028.2$ & 3,7 & 11,77 & 8,07 & 4,0 \\
\hline $\mathbf{A}_{6}$ & Estável & 18 & $1,028.8$ & 3,7 & 12,18 & 8,48 & 4,0 \\
\hline $\mathbf{A}_{7}$ & Estável & 17 & $1,029.1$ & 3,8 & 12,20 & 8,40 & 4,0 \\
\hline $\mathbf{A}_{8}$ & Estável & 16 & $1,027.2$ & 3,4 & 11,11 & 7,71 & 3,8 \\
\hline A9 & Instável & 12 & $1,029.2$ & 3,8 & 12,10 & 8,30 & 5,5 \\
\hline $\begin{array}{c}\text { Padrão IN } \\
76 / 2018\end{array}$ & Estável & 14 a 18 & 1,028 a 1,034 & $>\mathbf{3 , 0}$ & $>11,40$ & $>8,4$ & $\leq 4,0$ \\
\hline
\end{tabular}

EST: extrato seco total, ESD: extrato seco desengordurado. Fonte: Autores.

Verificou-se neste trabalho que $1 / 3$ das amostras $\left(\mathrm{A}_{4}, \mathrm{~A}_{5}\right.$ e $\left.\mathrm{A}_{9}\right)$ analisadas apresentaram resultados em desacordo com a legislação vigente em relação ao teste de alizarol (Tabela 2). A amostra $\mathrm{A}_{4}$ apresentou-se ligeiramente ácida, com formação de grumos. Segundo Castanheira (2010), o teste do alizarol busca verificar a instabilidade do leite quando há grande formação de grumos e sua coloração poderá ser violeta ou amarelada, sendo frequentemente rejeitada pelas indústrias, onde um dos redutores de acidez mais utilizados é o bicarbonato de sódio. A amostra $\mathrm{A}_{5}$ apresentou coloração salmão com formação de grumos, sendo considerado como leite instável não ácido (LINA). Segundo Zanela (2004), a principal alteração observada no LINA é a ausência de estabilidade da proteína caseína ao álcool, resultando em precipitação positiva, sem haver acidez elevada do leite. Souza et al., (2016), ao pesquisarem a ocorrência do LINA na região norte do Mato Grosso, verificaram que das 486 amostras de leite analisadas, 35,4\% (172) foram instáveis, apresentado uma incidência de 13,95\% de LINA, as quais foram submetidas ao teste de acidez Dornic e apresentaram acidez abaixo de $18^{\circ} \mathrm{D}$. A amostra A9 apresentou coloração violeta arroxeada, o que evidencia fraude com adição de produto alcalino e água. Conforme legislação vigente (Brasil, 2018a), não é permitida a adição de conservantes, substâncias capazes de corrigir o pH, de aditivos ou de substâncias coadjuvantes de tecnologia/elaboração no leite cru.

De acordo com os dados apresentados a Tabela 2, a acidez do leite expressa em Dornic $\left({ }^{\circ} \mathrm{D}\right)$ oscilou em torno de 12 a $20^{\circ} \mathrm{D}$ nas amostras coletadas nos tanques de refrigeração. O valor determinado pelo método Dornic, análise quantitativa, reafirma a não conformidade das amostras $\mathrm{A}_{4}, \mathrm{~A}_{5}$ e $\mathrm{A}_{9}$ quanto à estabilidade avaliada no teste do alizarol. Valores de acidez acima de $18^{\circ}$ Dornic indicam proliferação bacteriana, podendo indicar qualidade microbiológica inadequada, conforme relatado por Arbello et al. (2021). Já uma baixa acidez pode ser resultado de fraude por adição de substâncias alcalinizantes, a fim de se reduzir uma elevada acidez provocada por alto índice de bactérias indesejáveis (Castanheira, 2010). Os resultados deste trabalho foram semelhantes aos relatados por Barbosa et al. (2014), ao detectarem que 1/3 das amostras de leite cru avaliadas no Estado da Paraíba, para densidade, acidez titulável e gordura não atenderam aos padrões exigidos. Melo et al. (2018), ao avaliarem amostras de leite cru refrigerado coletadas em tanques de expansão de 10 produtores individuais no Paraíba, detectaram valores variaram entre $13,60^{\circ} \mathrm{D}$ a $20,66^{\circ} \mathrm{D}$, com apenas $20 \%$ das amostras em desacordo com a IN $76 / 2018$ (Brasil, 2018a).

$\mathrm{Na}$ determinação dos valores de densidade a $15^{\circ} \mathrm{C}$ (Tabela 2), grande parte das amostras $(88,88 \%)$ encontraram-se dentro dos padrões, sendo coerentes com a variação de 1,028 a 1,034 $\mathrm{g} \mathrm{mL}^{-1}$, indicando a qualidade nutricional das amostras. Já a amostra $\mathrm{A}_{8}$, apresentou um valor abaixo $\left(1,027.2 \mathrm{~g} \mathrm{~mL}^{-1}\right)$ sugerindo possível fraude com adição de água. De acordo com Silva et al. (2008), a adição de água também reduz o valor nutricional do leite porque altera a relação dos seus constituintes. A 
densidade do leite é variável, dependendo de sua composição e serve para controlar, até certos limites de fraudes, a desnate prévia ou adição de água. Amostras com densidades abaixo ou acima do que determina a IN 76/2018 (Brasil, 2018a) acarreta a rejeição do leite cru refrigerado no momento da recepção, pois esta densidade pode ser devida a fraudes como adição de água ou seu desnate nas propriedades (Zenebon, et al., 2008). Fernandes \& Maricato (2010) ressaltaram que a ausência de fraude no leite cru indica qualidade adequada e uma maior conscientização dos produtores, que colaboram para atendimento aos critérios estabelecidos na legislação.

Para as análises referentes ao teor de gordura, a IN 76/2018 (Brasil, 2018a) estabelece que o leite cru refrigerado apresente valor de no mínimo 3,0\%. Todas as amostras analisadas neste trabalho apresentaram teor de Gordura (Tabela 2) acima do mínimo de 3,0\%, estando, portanto, adequadas quanto a este parâmetro. Silva et al., (2017) obtiveram valores médios de 3,86 a 4,95 $100 \mathrm{~g}^{-1}$ estando de acordo com o preconizado pela legislação. O teor de gordura é determinante no preço final da matéria prima, em especial em indústrias de derivados do leite, ou seja, utilizam a gordura para produção de derivados específicos como creme de leite e manteiga (Tronco, 2008). Devido à importância para a produção de derivados e de seu alto valor comercial, a determinação exata do percentual de gordura no leite é primordial para a indústria de laticínios e produtores (Castanheira, 2010).

A percentagem de extrato seco total (EST) é um parâmetro indispensável para avaliar a integridade do leite. No presente estudo apenas a amostra $\mathrm{A}_{8}$ ficou abaixo do preconizado na legislação vigente (Tabela 2), podendo esse fato ser relacionando ao tipo de alimentação do rebanho, o que é confirmado por Mühlbach (2003). Melo et al. (2018) obtiveram resultados bem próximos aos relatados no presente estudo, o que sugere que pode haver uma correlação com alimentação do rebanho, pois ambos os estudos se fizeram no mesmo município.

Os resultados encontrados para os valores de extrato seco desengordurado - ESD (Tabela 2) foram insatisfatórios para 44,44\% das amostras, considerando o valor mínimo de 8,40\% (Brasil, 2018a). Silva et al. (2017) avaliaram o leite cru comercializado informalmente no município de Aparecida/PB e observaram que do total de 24 amostras de leite cru refrigerado analisadas, 62,5\% apresentaram percentuais de ESD fora dos padrões legais vigentes. Barbosa et al., (2014) ao avaliarem valores obtidos em sua pesquisa concluíram que 50\% das amostras de leite cru analisados foram detectados com valores abaixo do preconizado pela legislação vigente, não atendendo aos padrões exigidos.

Em relação aos valores de temperatura constatados nos tanques de refrigeração, observou-se um grande número de amostras $(44,44 \%)$ com valores acima dos $4^{\circ} \mathrm{C}$ no momento da coleta. Havia tanques desligados no horário da ordenha, como verificado na amostra $A_{1}$. Ressaltamos a importância da cadeia do frio na produção leiteira, o qual deve ser mantido refrigerado até seu transporte para a indústria, onde deverá chegar a $7^{\circ} \mathrm{C}$ (Brasil, 2018a). A refrigeração do leite cru na unidade de beneficiamento de leite e derivados pode ser de até $7^{\circ} \mathrm{C}$, porém o leite estocado deve apresentar uma contagem microbiológica máxima de 300.000 UFC/mL, segundo a IN 55/2020 (Brasil, 2020).

No presente estudo, constatou-se que aproximadamente $1 / 3$ das amostras $\left(A_{3}, A_{6}\right.$ e $\left.A_{7}\right)$ encontraram-se em conformidade com todos os parâmetros físico-químicos estabelecidos pela IN 76/2018 (Brasil, 2018a). É imprescindível a adoção de programas contínuos em educação higiênico-sanitária, além da implementação das boas práticas agropecuárias junto aos produtores, visando à melhoria da qualidade do leite armazenado nos tanques de refrigeração individuais e coletivos.

\section{Conclusão}

A qualidade de algumas amostras do leite cru armazenado sob refrigeração mostrou-se insatisfatória tanto em relação ao alto índice de contagem bacteriano quanto em relação às análises físico-químicas. Esforços são fundamentais e necessários por parte de todos os envolvidos na cadeia produtiva para que possam se adequar às condições de produção visando à melhoria 
da qualidade do leite.

Tudo isso contribuirá para obtenção de leite e seus derivados com qualidade e inocuidade, agregará valor aos produtos lácteos além de garantir a sustentabilidade do setor no município de Alegre e consequentemente em todo o estado do ES.

\section{Agradecimentos}

Ao Instituto Federal de Educação do Espírito Santo - Campus de Alegre, ES.

Ao Programa de Pós-Graduação em Agroecologia (PPGA/IFES - Campus Alegre) por possibilitar a realização desta pesquisa.

À Prefeitura Municipal de Alegre/ES pela colaboração e apoio logístico nas coletas das amostras de leite cru refrigerado nas propriedades rurais do município.

\section{Referências}

Arbello, D. D. R., Braccini, V. P., Jiménez, M. E., Erhardt, M. M. \& Richards, N. S. P. S. (2021). Análise microbiológica e físico-química do leite produzido na cidade de Santana do Livramento. Research, Society and Development, 10(6), 1-11.

Aguiar, G. S., Ulisses, A. F., Gomes, L. R., Rocha, L. I. R. \& Suhet, M. I. (2016) Avaliação da presença de antibiótico em leite cru refrigerado. Revista UNIVAP, 22(40).

Almeida, A. C., Santos, C. A., Menezes, I. R., Teixeira, L. M., Costa, J. P. R. \& Souza, R. M. (2016). Perfil sanitário de unidades agrícolas familiares produtores de leite cru e adequação à legislação vigente. Ciência Animal Brasileira, Goiânia, 17(3), 303-315.

American Public Health Association - APHA. (2001). Compendium of methods for the microbiological examination of foods. (4a ed.), APHA: Washington, $2001.676 \mathrm{p}$.

Assis, A. A., Faé, C. B., Donatele, D. M., Barioni, G., Clipes, R. C., Almeida, Í. C., Denadal, L. B., Sarmento, L. P., Almeida, S. L. H. \& Guerson, Y. B. (2017) Prevalência e etiologia da mastite bovina em municípios da região do Caparáó/ES. Revista Acadêmica Ciências Animal, 15(2), 285-286.

Ávila, F. A., Rigobelo, E. C. \& Maluta, R. P. (2011). Antibióticos, quimioterápicos e probióticos. FUNEP, cap. 20, p. 83.

Barbosa, H. P., Lima, C. U. G. B., Santana, A. M. F., Lins, A. A., Polizelli, M. \& Martins, P. S. (2014). Caracterização físico-química de amostras de leite in natura comercializados no estado da Paraíba. Revista Ciência Saúde Nova Esperança. (12), 2.

Bozo, G. A., Alegro, L. C. A., Silva, L. C., Santana, E. H. W., Okano, W. \& Silva, L. C. C. (2013). Adequação da contagem de células somáticas e da contagem bacteriana total em leite cru refrigerado aos parâmetros da legislação. Arquivo Brasileiro de Medicina Veterinária e Zootecnia, 65(2), 589-594.

Brasil. (2002). Ministério da Agricultura, Pecuária e Abastecimento. Instrução Normativa no 51, de 18 de setembro de 2002. Aprova o Regulamento técnico de identidade e qualidade de leite cru refrigerado. Diário Oficial da República Federativa do Brasil, 20/09/2002| Seção: 1 | Página: 13.

Brasil. (2011). Ministério da Agricultura, Pecuária e Abastecimento. Instrução Normativa nº 62, de 29 de dezembro de 2011. Aprova o Regulamento Técnico de Produção, Identidade e Qualidade do Leite tipo A, o Regulamento Técnico de Identidade e Qualidade de Leite Cru Refrigerado, o Regulamento Técnico de Identidade e Qualidade de Leite Pasteurizado e o Regulamento Técnico da Coleta de Leite Cru Refrigerado e seu Transporte a Granel, em conformidade com os Anexos desta Instrução Normativa. Diário Oficial da República Federativa do Brasil, 30/12/2011| Seção: 1 | Página: 6.

Brasil. (2018a). Ministério da Agricultura Pecuária e Abastecimento. Instrução normativa n. 76, de 26 de novembro de 2018. Aprova Regulamentos Técnicos que fixam a identidade e as características de qualidade que devem apresentar o leite cru refrigerado, o leite pasteurizado e o leite pasteurizado tipo A, na forma desta Instrução Normativa e do Anexo Único. Diário Oficial da União, 30/11/2018 | Edição: 230 | Seção: 1 | Página: 9.

Brasil. (2108b). Ministério da Agricultura, Pecuária e Abastecimento. Instrução Normativa $\mathrm{n}^{\circ}$. 77, de 26 de novembro de 2018. Estabelece os critérios e procedimentos para a produção, acondicionamento, conservação, transporte, seleção e recepção do leite cru em estabelecimentos registrados no serviço de inspeção oficial. Diário Oficial República Federativa do Brasil, 30/11/2018| Seção: 1 | Página: 10.

Brasil. (2018c). Ministério da Agricultura, Pecuária e Abastecimento. Instrução Normativa nº 30, de 26 de junho de 2018. Manual de Métodos Oficiais para Análise de Alimentos de Origem Animal. Diário Oficial da República Federativa do Brasil, 13/07/2018| Seção: 1 | Página: 9.

Brasil. (2020) Ministério da Agricultura, Pecuária e Abastecimento. Instrução Normativa Mapa ${ }^{\circ}$ 55, de 30 de setembro de 2020 - Altera a Instrução Normativa nº 76, de 26 de novembro de 2018. Diário Oficial República Federativa do Brasil, 30/09/2020| Edição: 189 | Seção: 1 | Página: 9.

Brito, M. A. P. \& Lange, C. (2005). Resíduos de antibióticos no leite. Embrapa Gado de Leite. Comunicado Técnico, 44, $1^{\text {a }}$ edição.

Carvalho, R. N. G., Oliveira, A. C. L. A., Silva, J. P. A. A., Anjos, C. F. C. \& Vieira, E. S. (2020). Detecção de resíduos de antibióticos em leite cru em fazendas de Aquidabã - Sergipe. PUBVET. 14(5), a578.

Castanheira, A. C. G. (2010). Manual básico de controle de qualidade de leite e derivados comentado, baseado em metodologias de análises físico-químicas e 
microbiológicas, contidas nas instruções normativas 68/2006 e 62/2003. CAPLAB - Indústria e Comércio Ltda.

Dürr, J. W. (2012). Como produzir leite de qualidade. (4a ed.), SENAR, 44 p.

Empresa Brasileira de Pesquisa Agropecuária - EMBRAPA. (2020). Anuário leite 2020: leite de vacas felizes, 102 p.

Espinola, W. R., Nascente, E. P., Urzêda, M., Teodoro, J. V. S., Gonçalves, G. B., Castro, R. D., Martins, M. E. P. \& Souza, W. J. (2020). Qualidade do leite cru refrigerado produzido na microrregião de Pires do Rio, Goiás, Brasil. Research, Society and Development, 9(7),1-15.

Food and Agriculture Organization of the United Nations - FAO. (2016). The FAO action plan on antimicrobial resistance 2016-2020.

Fernandes, V. G. \& Maricato, E. (2010). Análises físico-químicas de amostras de leite cru de um laticínio em Bicas, MG. Revista do Instituto de Laticínios Cândido Tostes, 65(375),.3-10.

Instituto Capixaba de pesquisa, assistência técnica e extensão Rural- INCAPER. (2019). Sistema de Informações Gerenciais do Serviço de Inspeção Federal.

Instituto Capixaba de pesquisa, assistência técnica e extensão Rural- INCAPER. (2020). Programa de Assistência Técnica e Extensão Rural - Proater 20202023 .

Lamaita, H. C., Cerqueira, M. M. O. P., Carmo, L. S., Santos, D. A., Penna, C. F. A. M. \& Souza M. R. (2005). Contagem de Staphylococcus sp. e detecção de enterotoxinas estafilocócicas e toxina da síndrome do choque tóxico em amostras de leite cru refrigerado. Arquivo Brasileiro de Medicina Veterinária e Zootecnia. 57(5),702-709.

Lampugnani, C., Perin, A. P., Ziech, R. E., Júnior, O. A. C., Montanhini, M. T. M. \& Bersot, L. S. (2018). Qualidade do leite cru refrigerado e características da produção leiteira na mesorregião oeste paranaense, Brasil. Revista do Instituto de Laticínios Cândido Tostes. 73(1), 19-26.

Medeiros, N. C., Abrantes, M. R., Medeiros, J. M. S., Campêlo, M. C. S., Rebouças, M. O., Costa, M. G. A. \& Silva, J. B. A. (2017). Quality of milk used in informal artisanal production of coalho and butter cheeses. Semina: Ciências Agrárias, 38(4), 1955-1962.

Melo, C. W. B., Barbosa, F. R. \& Pereira, D. E. (2018). Avaliação da qualidade do leite cru refrigerado obtido em propriedades rurais localizadas na Paraíba. Revista Brasileira de Produtos Agroindustriais, 20(2),137-142.

Menezes, I. R., Almeida, A. C., Morão, R. P., Reis, S. V. R., Santos, C. A. \& Lopes, I. L. N. (2015). Qualidade microbiológica do leite cru produzido no Norte de Minas Gerais. Revista Brasileira de Ciência e Veterinária, 22(1), 58-63.

Mühlbach, P. R. F. (2003). Nutrição da vaca em lactação e a qualidade do leite. In: Simpósio de Bovinocultura de Leite, Chapecó. Sociedade Catarinense de Médicos Veterinários.

Neta, F. C. N., Junqueira, M. S., Carneiro, J. C. S., Ramos, M. P. Piccolo., Abdallah, F. R. \& Fracalossi, C. P. (2015). Condições de produção de leite em propriedades familiares localizadas no município de Alegre - ES, Brasil. Revista do Instituto de Laticínios Cândido Tostes, 70(3), 117-131.

Neta, F. C. N., Junqueira, M. S., Carneiro, J. C. S., Ramos, M. P. Piccolo., Pinto, C. L. O. \& Rosário, D. K. A. (2016). Avaliação da qualidade de leite cru armazenado em tanques de refrigeração no município de Alegre, Espírito Santo. Revista Brasileira de Agropecuária Sustentável, 6(3), 21-27.

Neta, F. C. N., Carneiro, J. C. S., Ramos, M. P. Piccolo., Junqueira, M. S., Fracalossi, C. P. \& Rosário, D. K. (2018). Diagnóstico de práticas adotadas pelos responsáveis do local de recepção e manutenção do leite cru refrigerado em tanques coletivos. Anais..., IX Simpósio Brasileiro de Agropecuária Sustentável VI Congresso Internacional de Agropecuária Sustentável, p.23-27.

Nunes, M. T. \& D`Angelo, J. L. (2007). Ocorrência de resíduos de antibióticos no leite, em fazendas produtoras e no leite pronto para consumo. Revista Higiene Alimentar. 21, 57-61.

Oliveira, P. V. C., Neto, E. S. L., Lucena, N. M., Abrantes, M. L., Silva, J. B. A \& Neto, C. O. A. (2020). Avaliação da qualidade do leite cru e prevalência de mastite no município de Mossoró-RN. Brazilian Journal of Development, 6(8), 64027-64042.

Peixoto, A. L., Silva, M. A. P., Morais, L. A., Silva, F. R., Carmo, R. M. \& Lage, M. E. (2016). Influência do tipo de ordenha e do armazenamento do leite sobre a composição química, contagem de células somáticas e contagem bacteriana total. Revista do Instituto de Laticínios Cândido Tostes, 71(1), 10-18.

Piccolo, M. P., Santos, Y. I. C., Machado, T. M. F., Donatele, D. M. \& Júnior, G. A. A. (2018) Parâmetros de qualidade de leite cru refrigerado obtido de propriedades de base familiar. Anais..., IX Simpósio Brasileiro de Agropecuária Sustentável - VI Congresso Internacional de Agropecuária Sustentável, 23-27.

Rangel, A. H. N., Araújo, V. M., Bezerra, K. C., Barreto, M. L. J., Medeiros, H. R., Júnior, D. M. L. (2013). Avaliação da qualidade do leite cru com base na contagem de células somáticas em rebanhos bovinos comerciais no estado do Rio Grande do Norte, Brasil. Archives of Veterinary Science, $18(1)$,.40-45.

Ramos, M. P. Piccolo, Pinto, C. L. O., Carvalho, S. L., Cangussú, L. V., Freitas, R. A. \& Lacerda, J. S. J. (2014). Qualidade microbiológica e fatores que influenciam a produção de leite obtido de propriedades familiares no norte do Estado do Espírito Santo. Revista Brasileira de Agropecuária Sustentável, 4(1), $1-15$.

Santana, E. H. W., Beloti, V., Oliveira, T. C. R. M., Morais, L. B., TamaniniI, R. \& Sil, W. P. (2006). Estafilococos: morfologia das colônias, produção de coagulase e enterotoxina a, em amostras isoladas de leite cru refrigerado. Seminário: Ciências Agrárias, 27(4), 639-646.

Silva, M. C. D., Silva, J. V. L., Ramos, A. C. S., Melo, R. O. \& Oliveira, J. O. (2008). Caracterização microbiológica e físico-química de leite pasteurizado destinado ao programa do leite no Estado de Alagoas. Ciência e Tecnologia de Alimentos, 28(1), 226- 230.

Silva, G. W. N., Oliveira, M. P., Leite, K. D., Oliveira, M. S., Sousa, B. A. A. (2017). Avaliação físico-química de leite in natura comercializado informalmente no Sertão Paraibano. Revista Principia. Divulgação Científica e Tecnológica do IFPB, 35, 34-41. 
Research, Society and Development, v. 11, n. 1, e48111123708, 2022

(CC BY 4.0) | ISSN 2525-3409 | DOI: http://dx.doi.org/10.33448/rsd-v11i1.23708

Souza, H. P. M., Romero, N. B. \& Rosa, C. C. B. (2016). Ocorrência do leite instável não ácido (lina) na região Norte do Mato Grosso. Revista do Instituto de Laticínios Cândido Tostes, 71(1), 38-42.

Teixeira, S. R., Mendonça, L. C., Dutra, A. S. \& Monteiro, R. P. (2018). Manual de manutenção da qualidade do leite cru refrigerado armazenado em tanques coletivos para produtores, técnicos, transportadores e coletadores de amostras de leite. Documentos, 213. Embrapa Gado de Leite, Juiz de Fora, 25 p.

Toaldo, I. M., Gamba, G. Z., Picinin, L. A., Rubensam, G., Hoff, R. \& Bordignon-Luiz, M. (2012). Multiclass analysis of antibacterial residues in milk using RP-liquid chromatography with photodiode array and fluorescence detection and tandem mass spectrometer confirmation. Talanta, 99, 616-624.

Tronco, V. M. (2008). Manual para inspeção da qualidade do leite. (3a ed.), Ed. da UFSM.

Ulisses, A. F., Píccolo, M. P., Rangel, O. J. P., Suhet, M. I., Daros, I. U. \& Lo Monaco, P. A. V. (2019). Qualidade microbiológica e detecção de resíduos de antibióticos em leite cru refrigerado. Boletim Técnico $\mathrm{N}^{\mathrm{o}} 2$ (Desenvolvimento de material didático ou instrucional - Produto Tecnológico). <http://educapes.capes.gov.br/handle/capes/561011>.

Vasudevan, P., Nair, M. K. M. \& Annamalat, T. A. (2003). Phenotypic and genotypic haracterization of bovine mastitis isolates of Staphylococcus aureus for biofilm formation. Veterinary Microbiology, 92, 179-185.

Zanela, M. B. (2004). Caracterização do leite produzido no Rio Grande do Sul, ocorrência e indução experimental do Leite Instável Não Ácido (LINA). 2004. 143f. Tese (Doutorado em Zootecnia) - Faculdade de Agronomia Eliseu Maciel, UFPel.

Zenebon, O., Pascuet, N. S. \& Tiglea, P. (2008) Métodos físico-químicos para análise de alimentos. Instituto Adolfo Lutz. 27, 823-881. 